\title{
Memory for number of light flashes in the pigeon
}

\author{
WILLIAM A. ROBERTS, TODD MACUDA, and DAVID R. BRODBECK \\ University of Western Ontario, London, Ontario, Canada
}

\begin{abstract}
Two groups of pigeons were trained to perform symbolic delayed matching-to-sample at a 0 -sec delay with sample stimuli that consisted of sequences of light flashes. The sequences varied in number but not time for one group (number group) and in time but not number for the other group (time group). When retention was tested at delays up to $10 \mathrm{sec}$ in Experiment 1, a choose-small effect was found in the number group, and a choose-long effect was found in the time group. Transfer tests between number and time samples in Experiment 2 supported the hypothesis that pigeons were discriminating between the number of light flashes at the end of sample sequences in Experiment 1 . It was concluded that pigeons in both the number and the time groups were discriminating between number of flashes and that the apparent choose-long effect was actually a choose-small effect. The implications of these findings for the mode-control model of counting and timing (Meck \& Church, 1983) were discussed.
\end{abstract}

A number of experiments indicate that animals can form accurate discriminations on the basis of both time and number. Both rats and pigeons can learn to make different responses following signals that lasted for short (2-sec) or long (8-sec) time intervals (see, e.g., Meck \& Church, 1982; Roberts, Cheng, \& Cohen, 1989). Similarly, rats can learn to discriminate three noise bursts from two and four noise bursts (Davis \& Albert, 1986), and pigeons can learn to discriminate two light flashes from eight light flashes (Roberts \& Mitchell, 1994).

Meck and Church (1983) presented rats with sequences of 0.5 -sec bursts of white noise at the rate of one burst/ second. Subjects were trained to press different levers following two bursts $/ 2 \mathrm{sec}$ and eight bursts $/ 8 \mathrm{sec}$. When this discrimination was well established, probe tests for time and number control were inserted among training trials. Time control was examined by presenting four bursts over time intervals varying from 2 to $8 \mathrm{sec}$. Number control was measured by presenting sequences of bursts that lasted $4 \mathrm{sec}$ but varied in number from 2 to $8 \mathrm{sec}$. Rats showed strong control of choice behavior by both the time and number dimensions. Results similar to these were reported by Roberts and Mitchell (1994, Experiments 1-3) for pigeons trained and tested with sequences of light flashes.

These findings and a number of others have been accounted for by an information processing model advanced by Church, Meck, and Gibbon (Church \& Meck, 1984; Gibbon, 1977; Gibbon \& Church, 1984; Meck \& Church, 1983). A diagram of a slightly modified version of this

This research was supported by a Natural Sciences and Engineering Research Council grant held by W. A. Roberts. Reprint requests should be sent to W. A. Roberts, Department of Psychology, University of Western Ontario, London, ON Canada N6A 5C2 (e-mail: roberts@vaxr. sscl.uwo.ca).

- Accepted by previous editor, Vincent M. LoLordo model is shown in Figure 1. The model holds that pulses emitted at a fixed rate by a pacemaker are accumulated and transmitted to working memory. To account for the finding that animals simultaneously process time and number, it is assumed that separate switches and accumulators operate in run and event modes for processing time and number, respectively. In the run mode, a switch closes at the beginning of a sequence of stimuli and allows pulses to accumulate for the duration of the sequence. In the event mode, a switch would stay closed only for a short period each time a stimulus event occurs. On the basis of rats' transfer of discrimination between continuous noise signals to segmented noise signals, Meck, Church, and Gibbon (1985) estimated that the counting switch stayed closed for $200 \mathrm{msec}$ after the initiation of each stimulus. When a sequence of stimuli is processed, the model assumes that both modes operate simultaneouly and that pulses accumulate in both the time and number accumulators. If we assume, as a hypothetical example, that pulses are emitted from the pacemaker at the rate of $1 / \mathrm{msec}$, then a signal consisting of two bursts or flashes in $2 \mathrm{sec}$ would lead to the accumulation of 2,000 pulses in the time accumulator and 400 pulses in the number accumulator; a signal consisting of eight bursts or flashes in $8 \mathrm{sec}$ would lead to the accumulation of 8,000 pulses in the time accumulator and 1,600 pulses in the number accumulator. These accumulated totals are then transmitted to working memory where they direct responses through learned response rules stored in reference memory.

Roberts and Mitchell (1994, Experiments 4-5) recently showed that pigeons can learn to respond accurately to sequences of light flashes that are ambiguous. That is, pigeons were presented with sequences that required different responses (peck left or right side key) to the time and number attributes of the sequence. Pigeons were able to respond accurately to memory of these ambiguous sequences when postsequence cues (side key 


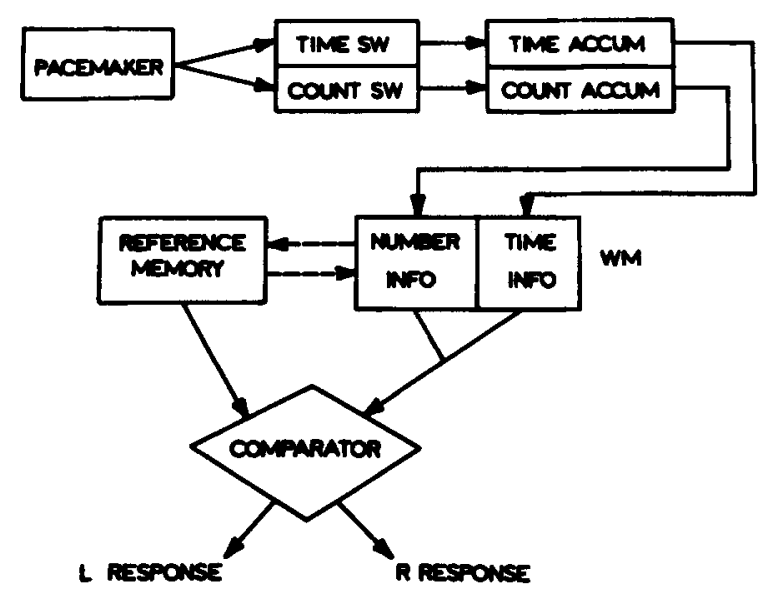

Figure 1. Diagram of a mode-control model for processing time and number information.

color) served to disambiguate the sequence. For example, red side keys were a cue to respond on the basis of time, and green side keys were a cue to respond on the basis of number. On the basis of these findings, Roberts and Mitchell suggested an extension of the mode control model of timing and counting in which time and number accumulations are stored in separate locations in working memory, as seen in Figure 1. Number or time information may be selectively retrieved from working memory by external retrieval cues.

An important basic assumption of the mode control model is that time and number are recorded by the same mechanism, the accumulation of pulses. The model predicts that manipulation of a variable that has an effect on memory for either time or number should have the same effect on memory for the other dimension. One test of that prediction is presented here.

In some temporal discrimination experiments that have been performed with pigeons, birds are trained to discriminate between two light signals, such as a houselight that stays on for $2 \mathrm{sec}$ versus one that stays on for $8 \mathrm{sec}$. A symbolic delayed matching-to-sample procedure is used in which the 2- and 8-sec houselights are sample stimuli and are mapped onto visually different comparison stimuli-say, red and green fields projected on side keys. Pigeons may learn to peck the red key after the 2sec sample and the green key after the 8-sec sample. Training takes place at a 0 -sec delay, so that comparison stimuli appear just as the sample stimulus terminates. When pigeons have achieved a high level of accuracy with this training procedure, extended memory tests are carried out by interpolating delays lasting up to 10 or $20 \mathrm{sec}$ between the end of the sample stimulus and the presentation of the comparison stimuli. The behavioral consequence of these memory tests is a pattern of data called the choose-short effect. Although memory for the 2 - and 8-sec duration houselights is equally good at a 0 sec delay, the retention curve for the 8-sec sample drops precipitously over delays to a level below chance $(50 \%$ accuracy) while the curve for the 2-sec sample drops far more slowly over delay intervals. As the delay becomes longer, pigeons show an increasing preference for the comparison key mapped onto the short sample duration (Kraemer, Mazmanian, \& Roberts, 1985; Spetch, 1987; Spetch \& Rusak, 1989; Spetch \& Wilkie, 1982, 1983).

Several lines of evidence suggest that the choose-short effect may be accounted for best by a process of subjective shortening of memory for time (Grant \& Spetch, 1993; Spetch \& Sinha, 1989; Spetch \& Wilkie, 1983; Wilkie \& Willson, 1990). Memory for time is assumed to foreshorten over a delay period, leading a pigeon to remember a long sample duration as a relatively short duration and to therefore show a preference for the shortsample comparison stimulus. If the process of subjective shortening is applied to the mode-control model discussed above, it implies that pulse counts residing in working memory diminish over a delay period. Suppose that pulse counts are halved over a delay period of $10 \mathrm{sec}$. The initial count of 8,000 for the 8 -sec sample would then be 4,000 , and the initial count of 2,000 for the 2 -sec sample would be 1,000 . The remembered count of 1,000 for the 2-sec sample would still be closer to the reference memory value of 2,000 than to the value of 8,000 and should yield little evidence of forgetting. However, the remembered count of 4,000 for the 8 -sec sample now also is closer to the reference memory value of 2,000 than to the value of 8,000 , and preference for the comparison stimulus corresponding to the short sample should appear.

Comparable predictions can be made for memory of number. If we assume that the initial memory for number is lost at the same rate as is the memory for time, the pulse count in working memory for two flashes should halve from 400 to 200 over a $10-\mathrm{sec}$ delay, and the pulse count for eight flashes should halve from 1,600 to 800 . Just as with time, the reduced values for both the small and the large number will be closer to the small number value in reference memory, and the comparison stimulus corresponding to the small number or two-flash comparison stimulus should be preferred after both samples. Retention curves for number should show a choose-small effect analogous to the choose-short effect found for time.

\section{EXPERIMENT 1}

Fetterman and MacEwen (1989) carried out an investigation of memory for number of responses in pigeons and found a choose-small effect. They used a symbolic delayed matching procedure in which the sample stimuli were numbers of pecks required in order to complete fixed ratio (FR) 10 and FR 40 schedules, with responses to different comparison stimuli required after each FR. When memory for FRs was tested over delays up to $20 \mathrm{sec}$, the FR 40 retention curve dropped faster than the FR 10 retention curve. Although this finding suggests a choose-small effect for number, it is inconclusive because time was confounded with number. Pigeons had to take more time to complete an FR 40 schedule than an 
FR 10 schedule. If pigeons matched comparison stimulus choices to the time spent pecking, then an apparent choose-small effect may have been a choose-short effect.

In the present experiment, time and number were unconfounded by using sequences of sample stimuli that varied in rate of presentation and thus held time constant while number varied. A group of pigeons was trained to match sample stimuli that consisted of two light flashes in $4 \mathrm{sec}(2 \mathrm{f} / 4 \mathrm{sec})$ and eight light flashes in $4 \mathrm{sec}(8 \mathrm{f} / 4 \mathrm{sec})$. Following acquisition of this discrimination with a $0-\mathrm{sec}$ delay, subjects were tested at delays extending to $10 \mathrm{sec}$. A choose-small effect would appear as a steeper retention curve for the $8 \mathrm{f} / 4 \mathrm{sec}$ sample stimulus than for the $2 \mathrm{f} / 4 \mathrm{sec}$ sample stimulus.

In order to compare the magnitude of a possible choosesmall effect with that of a choose-short effect, a second group of pigeons was trained to match samples of lightflash sequences that varied in duration while number of flashes remained constant. The sample sequences consisted of four flashes in $2 \mathrm{sec}(4 \mathrm{f} / 2 \mathrm{sec})$ and four flashes in $8 \mathrm{sec}(4 \mathrm{f} / 8 \mathrm{sec})$. It was anticipated that the $4 \mathrm{f} / 8 \mathrm{sec}$ sample retention curve would be steeper than the $4 \mathrm{f} / 2 \mathrm{sec}$ retention curve.

\section{Method}

Subjects. Eight adult White Carneaux pigeons served as subjects. They were maintained at approximately $80 \%$ of their free-feeding weights throughout the experiment and had constant access to water and health grit. The birds were housed in individual cages in a room kept at $22^{\circ} \mathrm{C}$. Overhead fluorescent lights were turned on at 8:30 a.m. and turned off at 10:30 p.m. each day. Testing was carried out between 9:00 a.m. and 1:00 p.m. for 6 days a week.

Apparatus. The operant chamber measured $31 \times 35.5 \mathrm{~cm}$ (floor dimensions) $\times 35.3 \mathrm{~cm}$ (height). The front wall contained a row of three pecking keys, level with a pigeon's head, spaced $8 \mathrm{~cm}$ apart, center to center. Projectors mounted behind these keys illuminated them with colored light. The chamber also contained a $6-W$ light bulb mounted in the center of the ceiling. The bulb was covered with a jeweled red lens, and illumination of this light bathed the entire chamber in red light. An electromechanical food hopper provided mixed grain through a $6 \times 6 \mathrm{~cm}$ opening centered on the front wall below the pecking keys. All trial events and data recording were controlled by a computer.

Procedure. The pigeons initially were trained to peck the left and right side keys when the keys were illuminated with red and green light for grain reward. Once every bird was reliably pecking the side keys, training was begun. The 8 pigeons were divided randomly into two groups of 4 subjects each: a number group and a time group. Both groups then were trained for a period of 20 days, with 48 trials in each daily session.

The sample sequences of light flashes are shown in Figure 2, with each sequence terminating on the right side of the figure at the point where comparison stimuli would appear during training. The overhead red light flashed on and off throughout a sequence; each light flash lasted $200 \mathrm{msec}$, with flashes spaced at equal time intervals throughout a sequence. During each daily session, pigeons in the time group had the $4 \mathrm{f} / 8 \mathrm{sec}$ sample presented on 24 trials and the $4 f / 2 \mathrm{sec}$ sample presented on the other 24 trials, with these trials randomly intermixed. Red and green light appeared on the side keys as comparison stimuli after each sample, with red the correct choice after $4 \mathrm{f} / 8 \mathrm{sec}$ and green the correct choice after $4 \mathrm{f} / 2 \mathrm{sec}$. The left-right positions of the red and green keys was balanced within the trials devoted to each sample sequence. For pigeons in the number group, the $8 \mathrm{f} / 4 \mathrm{sec}$ sample and the $2 \mathrm{f} / 4 \mathrm{sec}$
TIME GROUP

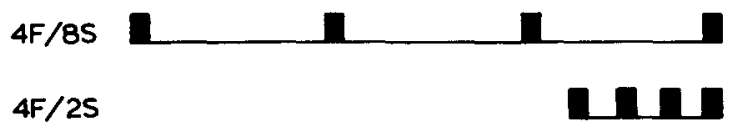

NUMBER GROUP

$8 F / 45$

นกnบn

$2 F / 4 S$

Figure 2. Sequences of light flashes used as sample stimuli in the time and number groups. Each filled space above the baseline represents a 200-msec light flash.

sample each were presented for 24 trials, with red the correct comparison stimulus after $8 \mathrm{f} / 4 \mathrm{sec}$ and green the correct choice after $2 \mathrm{f} / 4 \mathrm{sec}$. Correct choices led to $2 \mathrm{sec}$ of access to grain reward from the food hopper, and incorrect choices led to no reward and the initiation of the intertrial interval. The intertrial interval, spent in darkness, varied randomly between 10 and $30 \mathrm{sec}$.

After acquisition of matching was complete, pigeons in both groups were given 10 days of testing at several delays. Within daily sessions of 48 trials, delays of $0,2,5$, and $10 \mathrm{sec}$ were placed between the end of a sample sequence and the presentation of the comparison stimuli. Delay intervals were tested in random order, with each delay tested on 6 trials with each of the two sample sequences. As in training, correct responses were rewarded, and incorrect responses were not.

\section{Results}

Throughout these experiments, statistical tests were considered to be significant if $p<.05$.

Acquisition proceeded from near $50 \%$ accuracy on Session 1 to over $85 \%$ accuracy by both groups during the final sessions of training. Over Days 16-20 of acquisition, the levels of accuracy were $87.5 \%$ correct for the time group and $92.1 \%$ correct for the number group. These means did not differ significantly $[t(6)=1.13]$.

Retention curves based on data from the 10 test sessions are shown for the number group in Figure 3. These curves show clear evidence of a choose-small effect. Both curves begin at a high level of accuracy at the 0 -sec delay. At longer delays, however, the $2 \mathrm{f} / 4 \mathrm{sec}$ curve shows almost no loss of accuracy while the $8 \mathrm{f} / 4 \mathrm{sec}$ curve drops steeply to less than $30 \%$ correct at the 10 -sec delay. A sample sequence $X$ delay analysis of variance (ANOVA) performed on these data yielded significant effects of sample sequence $[F(1,3)=35.60]$ and delay $[F(3,9)=$ 48.38] and a significant sample sequence $\times$ delay interaction $[F(3,9)=28.98]$.

The retention data from the time group provided a surprising result, as can be seen in Figure 4. Although we had anticipatted finding the standard choose-short effect, the curves show a strong choose-long effect. The $4 \mathrm{f} / 8 \mathrm{sec}$ curve actually shows some improvement in accuracy over increasing delay intervals. The $4 \mathrm{f} / 2 \mathrm{sec}$ curve begins somewhat above the $4 \mathrm{f} / 8 \mathrm{sec}$ curve at the $0-\mathrm{sec}$ delay but 


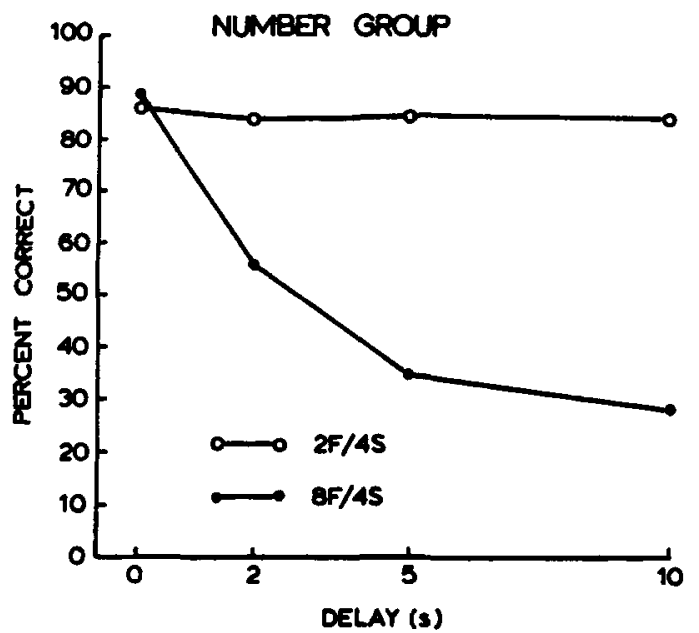

Figure 3. Retention of light-flash sequences over delays in the number group.

then drops sharply and ends up below $30 \%$ correct at the 10-sec delay. An ANOVA performed on these data showed significant effects of sample sequence $[F(1,3)=18.62]$ and delay $[F(3,9)=49.72]$ and a significant sample sequence $\times$ delay interaction $[F(3,9)=28.26]$.

\section{Discussion}

The discovery of a clear choose-small effect in the number group supports the hypothesis derived from the mode-control model that memory for time and number involve a common process. The rapid drop with increasing delay in the $8 \mathrm{f} / 4 \mathrm{sec}$ curve but not the $2 \mathrm{f} / 4 \mathrm{sec}$ curve agrees with the notion that accumulated pulses in working memory from the event mode were lost over time. The parallel nature of choose-short and choose-small effects seem to strongly support the idea of a common timing and counting mechanism.

The surprising choose-long effect found in the time group, however, appears to be completely contradictory to previous findings of a choose-short effect. Why did pigeons show faster forgetting of $4 \mathrm{f} / 2 \mathrm{sec}$ than of $4 \mathrm{f} / 8 \mathrm{sec}$ ? We suggest as an explanation that pigeons used a processing strategy very different from the one we intended them to use when we set up the experiment. Our hypothesis is that pigeons in the time group, as well as in the number group, used number of flashes rather than time as the basis for discriminating between samples. Although this may seem unlikely, given that the numbers of flashes were equated in the sample sequences in the time group, birds may have used only the information at the end of those sequences and that would involve different numbers of flashes. Examine the time sequences in Figure 2 and suppose that a pigeon used only the information occurring over the last $4 \mathrm{sec}$. Over that period, there were four flashes in the $4 \mathrm{f} / 2 \mathrm{sec}$ sequence and two flashes in the $4 \mathrm{f} / 8 \mathrm{sec}$ sequence. If pigeons used these numbers of flashes as sample stimuli, then $4 \mathrm{f} / 8 \mathrm{sec}$ was actually a "small" number, and $4 \mathrm{f} / 2 \mathrm{sec}$ was actually a "large" num- ber. If memory for the "larger" number of flashes dropped over delays, a bird should show an increasing tendency to peck the "long" key-in other words, the same comparison stimulus which, from the bird's perspective, is correct after a "small" number of flashes. In brief, the explanation offered is that the effects seen in Figures 3 and 4 are both choose-small effects.

\section{EXPERIMENT 2}

In Experiment 2, we carried out a test of the hypothesis that pigeons in both groups in Experiment 1 were matching number samples and, thus, that the chooselong effect seen in the time group was actually a choosesmall effect. Pigeons in both the time and the number groups were retrained on their original training contingencies at the 0 -sec delay for several sessions to ensure a high level of matching accuracy. The birds in the number group were then transferred to training with the time samples $(\mathrm{N} \rightarrow \mathrm{T})$, and the birds in the time group were transferred to training with the number samples $(T \rightarrow N)$. Within each group, 2 of the 4 birds were transferred to contingencies which were consistent with the hypothesis tested, while the other 2 birds were transferred to contingencies inconsistent with the hypothesis. The four groups tested are shown in Table 1. As an example, the hypothesis holds that pigeons in the time group learned to choose the green comparison stimulus after $4 \mathrm{f} / 2 \mathrm{sec}$ because they remembered a relatively large number of flashes; they learned to choose the red comparison after $4 \mathrm{f} / 8 \mathrm{sec}$ because they remembered a relatively small number of flashes. These birds should then show positive transfer when transferred to number samples if the green comparison is correct after the large-number sample, $8 \mathrm{f} / 4 \mathrm{sec}$, and the red comparison is correct after the small-number sample, $2 \mathrm{f} / 4 \mathrm{sec}$. In the $\mathrm{T} \rightarrow \mathrm{N}$ inconsistent group, however, negative transfer should occur because these contingencies are reversed. For the same reasons,

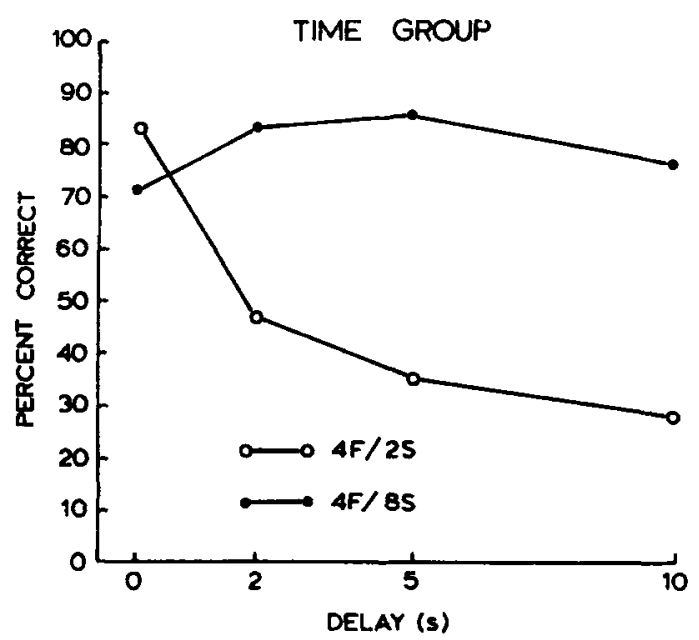

Figure 4. Retention of light-flash sequences over delays in the time group. 
the hypothesis predicts positive and negative transfer in $\mathrm{N} \rightarrow \mathrm{T}$ consistent and inconsistent groups, respectively. The alternative possibility that pigeons in the time group matched time samples leads to the prediction of no differential transfer between consistent and inconsistent conditions because birds will encounter completely new contingencies in both transfer conditions.

\section{Method}

Subjects and Apparatus. The same subjects and apparatus used in Experiment 1 were used in Experiment 2.

Procedure. The pigeons in the time and number groups in Experiment 1 were given 22 sessions of further training on symbolic delayed matching-to-sample at a 0 -sec delay. Each group was trained with the same sample stimuli and correct comparison stimuli used in Experiment 1.

On the basis of their performance over the last 5 days of training, the 4 subjects in each group were divided into two matched subgroups, each containing 2 subjects. One of the subgroups from the time group was tested on number samples with the samplecomparison contingencies consistent with the hypothesis tested (Group $\mathrm{T} \rightarrow \mathrm{N}$ consistent), and the other subgroup was tested on number samples with the sample-comparison contingencies inconsistent with the hypothesis (Group $\mathrm{T} \rightarrow \mathrm{N}$ inconsistent). Similarly, the subgroups from the number group were tested on time samples with the sample-comparison contingencies either consistent $(\mathrm{N} \rightarrow \mathrm{T}$ consistent) or inconsistent $(\mathrm{N} \rightarrow \mathrm{T}$ inconsistent) with the hypothesis (see Table 1).

Since the purpose of the experiment was to observe immediate transfer effects when pigeons were transferred from one problem to another, testing was carried out for only two sessions. All other procedural details were the same as those in Experiment 1.

\section{Results}

Over the final 5 days of retraining, the mean percentage of correct choices was $91.9 \%$ in the number group and $85.6 \%$ in the time group. These means did not differ significantly $[t(6)=1.86]$.

The transfer data are shown in Figure 5. Separate bars show the percent correct choices made by each pigeon over the two sessions of transfer testing. The data for transfer from both number samples to time samples and time samples to number samples agree with predictions from the hypothesis that both time and number groups based choices on differences in number. All 4 of the pigeons transferred to contingencies consistent with the hypothesis matched above chance, and all 4 of the pi-

Table 1

Design of Experiment 2

\begin{tabular}{|c|c|c|}
\hline Group & $\begin{array}{c}\text { Phase 1 } \\
\text { (Retrain) }\end{array}$ & $\begin{array}{c}\text { Phase } 2 \\
\text { (Transfer) }\end{array}$ \\
\hline & Number Samples & Time Samples \\
\hline $\mathrm{N} \rightarrow \mathrm{T}$ consistent & $\begin{array}{l}2 \mathrm{f} / 4 \mathrm{sec} \rightarrow \mathrm{G}^{+} \\
8 \mathrm{f} / 4 \mathrm{sec} \rightarrow \mathrm{R}^{+}\end{array}$ & $\begin{array}{l}4 f / 8 \sec \rightarrow G^{+} \\
4 f / 2 \sec \rightarrow R^{+}\end{array}$ \\
\hline \multirow[t]{2}{*}{$\mathrm{N} \rightarrow \mathrm{T}$ inconsistent } & $\begin{array}{l}2 \mathrm{f} / 4 \sec \rightarrow \mathrm{G}+ \\
8 \mathrm{f} / 4 \mathrm{sec} \rightarrow \mathrm{R}+\end{array}$ & $\begin{array}{l}4 \mathrm{f} / 8 \mathrm{sec} \rightarrow \mathrm{R}^{+} \\
4 \mathrm{f} / 2 \mathrm{sec} \rightarrow \mathrm{G}^{+}\end{array}$ \\
\hline & Time Samples & Number Samples \\
\hline & $\begin{array}{l}4 \mathrm{f} / 2 \sec \rightarrow \mathrm{G}^{+} \\
4 \mathrm{f} / 8 \sec \rightarrow \mathrm{R}^{+}\end{array}$ & $\begin{array}{l}8 \mathrm{f} / 4 \mathrm{sec} \rightarrow \mathrm{G}+ \\
2 \mathrm{f} / 4 \mathrm{sec} \rightarrow \mathrm{R}+\end{array}$ \\
\hline $\mathrm{T} \rightarrow \mathrm{N}$ inconsistent & $\begin{array}{l}4 \mathrm{f} / 2 \mathrm{sec} \rightarrow \mathrm{G}+ \\
4 \mathrm{f} / 8 \mathrm{sec} \rightarrow \mathrm{R}^{+}\end{array}$ & $\begin{array}{l}8 f / 4 \sec \rightarrow R+ \\
2 f / 4 \sec \rightarrow G+\end{array}$ \\
\hline
\end{tabular}

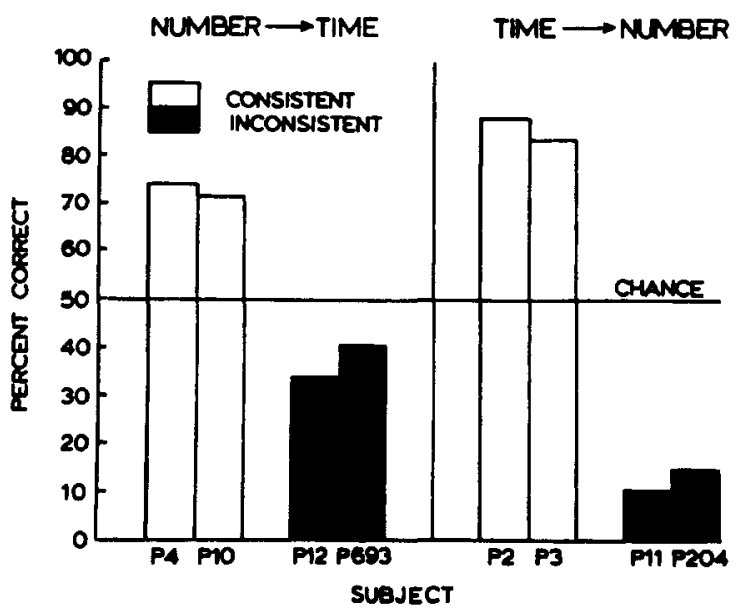

Figure 5. Percentage of correct (rewarded) responses made by each pigeon in Experiment 2. Transfer effects in $\mathbf{N} \rightarrow T$ and $T \rightarrow N$ groups are shown by the differences in accuracy between birds in consistent and inconsistent subgroups.

geons transferred to contingencies inconsistent with the hypothesis matched below chance.

An ANOVA performed on these data included as factors the direction of transfer $(\mathrm{N} \rightarrow \mathrm{T}$ vs. $\mathrm{T} \rightarrow \mathrm{N})$ and agreement of the sample-comparison contingencies with the hypothesis tested (consistent vs. inconsistent). The analysis yielded a significant effect of consistent versus inconsistent contingencies $[F(1,4)=560.54]$ and a significant interaction between the consistent versus inconsistent factor and the direction of transfer $[F(1,4)=54.57]$. The significant interaction arose from the fact that pigeons transferred from time to number showed larger positive and negative transfer effects under consistent and inconsistent conditions than did pigeons transferred from number to time.

\section{Discussion}

The findings of Experiment 2 strongly supported the hypothesis that pigeons both in the time and the number groups in Experiment 1 based their responding on differences in the numbers of light flashes occurring at the end of sample sequences. If a difference in number was the basis for matching in both groups, then birds should transfer easily in both directions between time and number samples as long as the mapping of sample-number to comparison stimulus was consistent between conditions. The clear evidence of positive transfer in all birds transferred to consistent conditions verified that prediction. By the same reasoning, transfer between sample types with the sample-comparison contingencies reversed should lead to negative transfer, and this effect was also seen clearly with birds in the inconsistent conditions.

\section{GENERAL DISCUSSION}

The findings of Experiment 1 showed clear evidence of a choose-small effect when pigeons were trained with 
sample stimuli equated for time but varying in number. As the retention interval became longer, the $8 \mathrm{f} / 4 \mathrm{sec}$ curve dropped steeply while the $2 \mathrm{f} / 4 \mathrm{sec}$ curve showed virtually no loss in accuracy. This finding further supports the mode control model of timing and counting by showing that there is a choose-small effect for number samples that parallels the choose-short effect found with time samples. Both effects can be explained by a loss of accumulated pulse counts from working memory over a delay interval.

The surprising appearance of a choose-long effect in the time group tested in Experiment 1 now can be understood as a choose-small effect. The strong transfer effects seen in Experiment 2 indicate that the time group was actually matching comparison stimuli to number of flashes seen at the end of each sample sequence. The sharp drop in the $4 \mathrm{f} / 2 \mathrm{sec}$ curve over delays can be attributed to the loss of pulse counts from working memory, and both retention effects seen in Experiment $I$ are consistent with the mode control model.

The interaction found in Experiment 2 further supports the idea that pigeons were matching the number of light flashes at the end of sample sequences. The observation that the degrees of positive and negative transfer were stronger when pigeons went from time to number than from number to time can be explained by the flash sequences shown in Figure 2. Suppose that pigeons remembered the number of flashes occurring over the final $4 \mathrm{sec}$ of each sequence. In the time group, the difference between the $4 \mathrm{f} / 8 \mathrm{sec}$ and $4 \mathrm{f} / 2 \mathrm{sec}$ samples over the final $4 \mathrm{sec}$ is two flashes versus four flashes. In the number group, however, the difference between the $8 \mathrm{f} / 4 \mathrm{sec}$ and $2 \mathrm{f} / 4 \mathrm{sec}$ samples over the final $4 \mathrm{sec}$ is eight flashes versus two flashes. Thus, the number group had a greater difference in number of final flashes between samples than did the time group, and this difference could make discrimination between samples easier in the number group. The number group showed a higher level of matching accuracy than did the time group both at the end of original training in Experiment 1 and at the end of retraining in Experiment 2, although neither of these differences was significant. Nevertheless, the stronger transfer effects seen in $\mathrm{T} \rightarrow \mathrm{N}$ transfer than in $\mathrm{N} \rightarrow \mathrm{T}$ transfer in Experiment 2 may arise from a greater ease of discriminating number in the number samples than in the time samples.

The finding that pigeons matched number of flashes at the end of sample sequences suggests a recency effect in sequence processing. That is, it appears that pigeons only used information at the end of flash sequences and not the entire sequence to form sample discriminations. Pigeon experiments on relative numerosity discrimination by Alsop and Honig (1991) support this position. Pigeons were presented with sequences of red and blue light flashes and had to peck different keys for reinforcement, depending on which color was presented more often. Subjects responded accurately to relative numerosity but were more influenced by flashes at the end of sequences than by those earlier in sequences. When time gaps of varying length were placed between the first and second flashes in a three-flash sequence, the relative effect on performance of the final two flashes over the initial flash increased as the gap became longer.

What does this conclusion imply about the modecontrol model? The model shown in Figure 1 indicates that animals accumulate total pulses in time and number accumulators until a sequence of signals has ended and then transmit those totals to working memory (Meck \& Church, 1983). Some elaboration of the model beyond this initial mechanism would seem to be necessary in order to account for recency effects. One assumption that could account for these results is that pulse counts begin to dwindle immediately after pulses begin to be transmitted at the initiation of a sequence of signals. In the $4 \mathrm{f} / 8 \mathrm{sec}$ sequence seen in Figure 2, for example, pigeons may remember the sequence as fewer than four flashes or $8 \mathrm{sec}$ in duration because number and time accumulations are being lost during the $8 \mathrm{sec}$ it takes to present the entire sequence. This suggestion is supported by Alsop and Honig's (1991) finding that the initial flash in a sequence has a declining impact on relative numerosity discrimination as the gap following it lengthens. Such a process would give more importance to short sequences or to the events occurring at the end of a long sequence.

\section{REFERENCES}

ALsop, B., \& HoNIG, W. K. (1991). Sequential stimuli and relative numerosity discriminations in pigeons. Journal of Experimental Psychology: Animal Behavior Processes, 17, 386-395.

Church, R. M., \& MECK, W. H. (1984). The numerical attribute of stimuli. In H. L. Roitblat, T. G. Bever, \& H. S. Terrace (Eds.), Animal cognition (pp. 445-464). Hillsdale, NJ: Erlbaum.

Davis, H., \& Al.BERT, M. (1986). Numerical discrimination by rats using sequential auditory stimuli. Animal Learning \& Behavior, 14, 57-59.

Fetterman, J. G., \& MacEwen, D. (1989). Short-term memory for responses: The "choose-small" effect. Journal of the Experimental Analysis of Behavior, 52, 311-324.

GibBon, J. (1977). Scalar expectancy theory and Weber's law in animal timing. Psychological Review, 84, 279-325.

Gibbon, J., \& ChURCh, R. M. (1984). Sources of variance in an information processing theory of timing. In H. L. Roitblat, T. G. Bever, \& H. S. Terrace (Eds.), Animal cognition (pp. 465-488). Hillsdale, NJ: Erlbaum.

GRANT, D. S., \& SPETCH, M. L. (1993). Analogical and nonanalogical coding of samples differing in duration in a choice-matching task in pigeons. Journal of Experimental Psychology: Animal Behavior Processes, 19, 15-25.

Kraemer, P. J., Mazmanian, D. S., \& Roberts, W. A. (1985). The choose-short effect in pigeon memory for stimulus duration: Subjective shortening versus coding models. Animal Learning \& Behavior, 13, 349-354.

MeCK, W. H., \& ChURCh, R. M. (1982). Abstraction of temporal attributes. Journal of Experimental Psychology: Animal Behavior Processes, 8, 226-243.

Meck, W. H., \& Church, R. M. (1983). A mode control model of counting and timing processes. Journal of Experimental Psychology: Animal Behavior Processes, 9, 320-334.

Meck, W. H., Church, R. M., \& Gibbon, J. (1985). Temporal integration in duration and number discrimination. Journal of Experimental Psychology: Animal Behavior Processes, 11, 591-597.

Roberts, W. A., Cheng, K., \& Cohen, J. S. (1989). Timing light and tone signals in pigeons. Journal of Experimental Psychology: Ani mal Behavior Processes, 15, 23-35. 
Roberts, W. A., \& Mitchell, S. (1994). Can a pigeon simultaneously process temporal and numerical information? Journal of Experimental Psychology: Animal Behavior Processes, 20, 66-78.

SPETCH, M. L. (1987). Systematic errors in pigeons' memory for event duration: Interaction between training and test delay. Animal Learning \& Behavior, 15, 1-5.

Spetch, M. L., \& RusaK, B. (1989). Pigeons' memory for event duration: Intertrial interval and delay effects. Animal Learning \& Behavior, 17, 147-156.

Spetch, M. L., \& Sinha, S. S. (1989). Proactive effects in pigeons memory for event duration: Evidence for analogical retention. Journal of Experimental Psychology: Animal Behavior Processes, 15, 347-357.
Spetch, M. L., \& Wilkie, D. M. (1982). A systematic bias in pigeons' memory for food and light durations. Behavior Analysis Letters, 2 , 267-274.

SPETCH, M. L., \& WilkiE, D. M. (1983). Subjective shortening: A model of pigeons' memory for event durations. Journal of Experimental Psychology: Animal Behavior Processes, 9, 14-30.

WILkIE, D. M., \& WILlson, R. J. (1990). Discriminal distance analysis supports the hypothesis that pigeons retrospectively encode event duration. Animal Learning \& Behavior, 18, 124-132.

(Manuscript received April 1 1, 1994; revision accepted for publication July 8, 1994.) 